\title{
Effect of different restorative procedures on the fracture resistance of teeth submitted to internal bleaching
}

\author{
Andiara Ribeiro Roberto(a) \\ Manoel Damião de Sousa-Neto(b) \\ Raqueli Viapiana ${ }^{(a)}$ \\ Alessandro Rogério Giovani(a) \\ Celso Bernardo de Souza Filho(a) \\ Silvana Maria Paulino(a) \\ Yara Teresinha Correa \\ Silva-Sousa ${ }^{(a)}$
}

(a) Dentistry Course, University of Ribeirão Preto, Ribeirão Preto, SP, Brazil.

(b) Department of Restorative Dentistry, School of Dentistry of Ribeirão Preto, University of São Paulo, SP, Brazil.

\begin{abstract}
The aim of this study was to evaluate the influence of different restorative procedures on the fracture resistance of endodontically treated teeth submitted to intracoronal bleaching. Fifty upper central incisors were distributed into 5 groups: GI - healthy teeth; GII - endodontically treated teeth sealed with Coltosol; GIII - endodontically treated teeth bleached and sealed with Coltosol; GIV - endodontically treated teeth bleached and restored with composite resin; and GV - endodontically treated teeth bleached and restored with a fiberglass post and composite resin. In the bleached specimens, a cervical seal was made prior to bleaching with $38 \%$ hydrogen peroxide. The gel was applied on the buccal surface and in the pulp chamber, and was then light-activated for $45 \mathrm{~s}$. This procedure was repeated three times per session for four sessions, and each group was submitted to the restorative procedures described above. The specimens were submitted to fracture resistance testing in a universal testing machine. There were statistically significant differences among the groups $(\mathrm{p}<0.05)$. The mean value found for GIII was the lowest $(0.32 \mathrm{kN})$ and was significantly different from the values found for GI $(0.75 \mathrm{kN})$, GII $(0.67 \mathrm{kN})$, GIV $(0.70 \mathrm{kN})$, and GV $(0.72 \mathrm{kN})$, which were not significantly different from each other $(\mathrm{p}>0.05)$. The restorative procedures using composite resin were found to successfully restore the fracture resistance of endodontically treated and bleached teeth.
\end{abstract}

Descriptors: Tooth Bleaching; Endodontics; Dentistry, Operative; Tooth Fractures.

\section{Introduction}

Intracoronal dental bleaching is commonly recommended for discertify that they have no commercial or associative interest that represents a conflict of interest in connection with the manuscript.

Corresponding author:

Manoel Damião de Sousa-Neto

E-mail:sousanet@forp.usp.br

Received for publication on Aug 31, 2011 Accepted for publication on Nov 18, 2011 
ing weakened dental structures. ${ }^{2,4}$

The use of composite resins with intraradicular posts has been recommended by some authors for restoring endodontically treated teeth submitted to dental bleaching, ${ }^{11,12}$ mainly owing to their ability to increase the fracture resistance of these teeth, whereas other authors claim that intraradicular posts should be recommended only when there is loss of more than half of the dental crown, for the purpose of connecting the prosthetic crown to the remaining root structure, or when intense occlusal forces are at play. ${ }^{13,14}$

Few studies have investigated different restorative procedures to minimize the damage caused by the loss of dental tissue resulting from endodontic treatment, on one hand, and by the changes in dental structure resulting from dental bleaching, on the other. Therefore, the aim of this study was to analyze the influence of restorative procedures on the fracture resistance of endodontically treated teeth submitted to intracoronal bleaching with $38 \%$ hydrogen peroxide and light-activated with a LEDlaser system.

\section{Methodology}

The study protocol was reviewed and approved by the local Ethics Committee (\#218/07). Fifty healthy upper central incisors without root canal calcification or resorption were radiographically selected and examined at $20 \times$ magnification using a stereomicroscope (Leica Microsystems, Wetzlar, Germany) to discard those with fissures or cracks. The specimens were distributed into 5 groups $(\mathrm{n}=10)$ :

- GI - healthy teeth (control);

- GII - endodontically treated teeth sealed with Coltosol;

- GIII - endodontically treated teeth bleached and sealed with Coltosol;

- GIV - endodontically treated teeth bleached and restored with composite resin;

- GV - endodontically treated teeth bleached and restored with composite resin and fiberglass post.

All teeth, except for those in the control group, were submitted to endodontic treatment. The bio- mechanical preparation was carried out with $\mathrm{NiTi}$ instruments (Endo K3 rotary system; SybronEndo, Glendora, USA), and the teeth were obturated with thermomechanically compacted gutta-percha cones (Tanari, Manacapuru, Brazil) combined with zinc oxide-eugenol sealer (Endofill; Dentsply-Maillefer, Petrópolis, Brazil).

In the bleached specimens (groups III, IV and V), a cervical seal was made with zinc phosphate prior to bleaching. The teeth were stored at $37^{\circ} \mathrm{C}$ for $45 \mathrm{~min}$, to allow the zinc phosphate cement to set, then inserted into a metallic rectangular matrix (16.5 mm wide $\times 31.0 \mathrm{~mm}$ long) and further embedded in auto-polymerized acrylic resin (Jet Clássico, São Paulo, Brazil) up to the cementoenamel junction.

The bleaching agent used was 38\% hydrogen peroxide (Opalescence Xtra Boost; Ultradent Products, Inc., South Jordan, USA) activated by a LEDlaser system (Brightness; Kondortech, São Carlos, Brazil) at $50 \mathrm{nW}$. This device combines an infrared diode laser $(790 \mathrm{~nm})$ with a set of LEDs $(470 \mathrm{~nm})$. Each bleaching procedure consisted of applying the bleaching gel to the buccal surface and in the pulp chamber, followed by light activation for $45 \mathrm{~s}$ on both surfaces, with a 5 min interval and reapplication of light. The bleaching gel was removed by aspiration and the area was then irrigated with $1 \%$ sodium hypochlorite. This procedure was repeated 3 times in the same session.

The specimens were temporarily sealed with Coltosol (Vigodent, Rio de Janeiro, Brazil), stored in artificial saliva at room temperature for 7 days, and then submitted to a new bleaching session similar to that described previously.

After four sessions of dental bleaching, the specimens were stored at $37{ }^{\circ} \mathrm{C}$ and a 10 -day postbleaching interval was observed before initiating the restoration procedures. At the end of this period, the temporary restoration and the cervical seal were removed, and the teeth were grouped according to the restorative procedures performed, as described below:

- GII - Non-bleached teeth sealed with Coltosol;

- GIII - Teeth submitted to dental bleaching and sealed with Coltosol, from $3 \mathrm{~mm}$ below the cementoenamel junction (CEJ) up to the tooth 
crown;

- GIV - Teeth submitted to dental bleaching and restored with composite resin (Filtek Z250; 3M ESPE, St. Paul, USA) from $3 \mathrm{~mm}$ below the CEJ up to the tooth crown. All walls of the coronal access cavity were etched with $35 \%$ phosphoric acid (3M ESPE, St. Paul, USA) for $15 \mathrm{~s}$, washed with water and dried with absorbent paper. An adhesive system (Single Bond 3M ESPE, St. Paul, USA) was applied in two layers, using a microbrush (KG Sorensen, São Paulo, Brazil). A composite resin was inserted incrementally and then light-activated for $20 \mathrm{~s}$ using a halogen lamp (Ultralux electronic; Dabi Atlante, Ribeirão Preto, Brazil) at $600 \mathrm{~mW} / \mathrm{cm}^{2}$. The last layer was lightactivated for $40 \mathrm{~s}$.

- GV - Teeth submitted to dental bleaching and restored with intraradicular fiberglass posts (Exacto, Ângelus, Londrina, Brazil) and composite resin (Filtek Z250). The post space was prepared using a heated plugger to remove guttapercha up to $10 \mathrm{~mm}$ into the root canal, then washed with distilled water and dried with absorbent points. The fiberglass post was then selected and cleaned with alcohol, and a layer of silane (Ângelus, Londrina, Brazil) was applied to its surface. Excess silane was removed with compressed air for $5 \mathrm{~s}$. The fiberglass post was cemented with Panavia F 2.0 cement (Kuraray America, Inc., New York, USA), manipulated according to the manufacturer's recommendations. The cement was inserted into the root canal using a \#40 Lentulo bur and applied to the post surface. The post was then inserted into the canal in a single movement and kept under digital pressure for $60 \mathrm{~s}$. Excess cement was removed and the material was light-activated with a halogen lamp (Ultralux electronic; Dabi Atlante, Ribeirão Preto, Brazil) at $600 \mathrm{~mW} / \mathrm{cm}^{2}$ for $30 \mathrm{~s}$ on each tooth surface (buccal, palatal and proximal). After cementation, the remaining post length was cut off and final restoration of the palatal surface was carried out with composite resin, in the same way described for Group IV.
After $24 \mathrm{~h}$, the specimens were subjected to the fracture strength test using a universal testing machine (Instron 4444; Instron Corp., Canton, USA) with a cell load activated at a crosshead speed of $1 \mathrm{~mm} / \mathrm{min}$. The specimens were positioned at $135^{\circ}$ in relation to the root's long axis, and the load was applied to the palatal surface of the tooth $(3.0 \mathrm{~mm}$ from the incisal edge) with a rectangular roundtipped metal point. The moment of fracture was determined by a sudden decrease in the force measured in the testing machine.

The data were submitted to the non-parametric Kruskal-Wallis and Dunn's post-hoc tests using Graph Instat Software (GraphPad Software Inc., San Diego, USA), at a significance level of $5 \%$.

\section{Results}

The means and standard deviations of strength $(\mathrm{kN})$ obtained for each group are presented in Table 1.

The Kruskal-Wallis test revealed statistically significant differences among the groups $(\mathrm{p}<0.05)$. The teeth submitted to bleaching and sealed with Coltosol (GIII) showed the lowest strength values $(0.30 \pm 0.21 \mathrm{kN})$, which were statistically different $(\mathrm{p}<0.05)$ from those of the other groups (GI, GII, GIV and GV). The mean fracture resistance values of the control group (GI) were the highest $(0.75 \pm 0.31 \mathrm{kN})$ and were not significantly different from those of groups II, IV and V ( $p>0.05)$, which were similar to each other $(p>0.05)$.

Table 1 - Mean and standard deviation (kN) of the maximum force needed to fracture the dental crowns, and Dunn's test comparisons.

\begin{tabular}{l|c|c}
\hline \multicolumn{1}{c|}{ Experimental groups } & \multicolumn{2}{|c}{ mean \pm SD } \\
\hline GI - Healthy teeth & $0.75 \pm 0.31$ & A \\
\hline GII - Endodontically treated + Coltosol & $0.67 \pm 0.27$ & A \\
\hline $\begin{array}{l}\text { GIII - Endodontically treated + Bleaching + } \\
\text { Coltosol }\end{array}$ & $0.32 \pm 0.20$ & B \\
\hline $\begin{array}{l}\text { GIV - Endodontically treated + Bleaching + } \\
\text { Resin }\end{array}$ & $0.70 \pm 0.25$ & A \\
\hline $\begin{array}{l}\text { GV - Endodontically treated + Bleaching + } \\
\text { Resin + Post }\end{array}$ & $0.72 \pm 0.24$ & A \\
\hline
\end{tabular}

Different letters indicate statistical difference $(p<0.05)$. 


\section{Discussion}

Tooth weakening is the main side effect of endodontic treatment ${ }^{15}$ and dental bleaching. ${ }^{16}$ Restoring the fracture resistance of endodontically treated teeth is becoming a greater focus of concern in dental research. ${ }^{12}$

The main factors involved in tooth structure loss are caries and root canal access preparation and instrumentation. ${ }^{17}$ According to the related literature, there is no consensus regarding reduced fracture resistance observed after endodontic treatment. ${ }^{18,19} \mathrm{Al}-$ though this was not the main objective of this study, the present results also revealed that the endodontic treatment did not reduce tooth fracture resistance, since the resistance values of the teeth submitted only to endodontic treatment and sealed with Coltosol (GII) were not significantly different from those of healthy teeth $(\mathrm{GI})$.

Until recently, increased susceptibility to fracture in endodontically treated teeth had been attributed to an increased brittleness of dentin as a result of moisture loss. ${ }^{20}$ Today, however, researchers stress that a loss of tooth structure is the key reason behind the observed increase in the fracture predisposition of endodontically treated teeth. ${ }^{21}$ In this study, endodontically treated teeth had a minimal loss of tooth structure and the irrigating solutions remained in contact with the dentin for only a short period of time. As a result, these teeth did not become more susceptible to fracture on account of the endodontic treatment.

According to the related literature, different bleaching agents or whitening techniques can adversely affect the fracture resistance of teeth, likely owing to changes in dental structure, such as those related to porosity, demineralization, decreased adhesion of restorative materials to dentin, increased dentin permeability, reduced dentin microhardness and decreased dentin diametral tensile strength. ${ }^{2,3,6,22}$ This effect was also observed in this study, since the fracture resistance values of the endodontically treated teeth submitted to dental bleaching and sealed with Coltosol (GIII) were the lowest $(0.31 \mathrm{kN})$ and statistically different from those of healthy teeth (GI), endodontically treated teeth and sealed with Coltosol (GII), endodontically treated teeth submitted to dental bleaching and restored with composite resin (GIV), and endodontically treated teeth submitted to dental bleaching and restored with composite resin combined with a fiberglass post (GV).

Another factor of great relevance that may be associated with the decrease in fracture resistance of bleached teeth is the number of applications of the bleaching agent to the dental surface. According to Pobbe et al., ${ }^{4}$ two or more sessions of dental bleaching with $38 \%$ hydrogen peroxide, activated by a LED-laser system, reduce the fracture resistance of endodontically treated teeth probably as a result of the action of hydrogen peroxide, which modifies the mechanical and chemical properties of dentin.

According to Kawamoto and Tsujimoto, ${ }^{23}$ the $\mathrm{OH}$ radical resulting from hydrogen peroxide degradation is responsible for tooth whitening, and acts on intertubular and peritubular dentin, destroying its organic portion, increasing permeability, ${ }^{24,25}$ and decreasing its hardness and elasticity modulus, ${ }^{2,3}$ which can be intensified with a greater exposure time of the tooth to the bleaching agent. This may explain the greater susceptibility to fracture observed in the teeth endodontically treated, bleached and only sealed with Coltosol (GIII).

It is also noteworthy to mention that some authors have reported that the heat applied to activate the bleaching agent or even produced by chemical reactions during this clinical procedure may cause reversible, or even irreversible, deleterious effects on dental and periodontal tissues. ${ }^{4,11,25}$ However, some studies have shown that this negative effect may be offset by the thermal insulating capability of dentin, which reduces the amount of heat reaching the pulp chamber significantly. ${ }^{12,18}$ Another important consideration is that low intensity laser irradiation may compensate the cytotoxic effect of a highly concentrated hydrogen peroxide gel. ${ }^{26}$

Although the results suggest a decrease in the fracture resistance of teeth submitted to dental bleaching (GIII), and restored only with composite resin (GIV) or with fiberglass post $(\mathrm{GV})$, no statistically significant difference was observed when these teeth were compared to healthy teeth (GI) and to those endodontically treated and sealed with Coltosol (GII). 
It seems that the restorative procedures restored the fracture resistance of endodontically treated teeth submitted to dental bleaching. This observation is in agreement with that of other studies ${ }^{12,15}$ reporting that composite resin is a suitable restorative material for weakened teeth, because it restores the tooth's fracture resistance up to values comparable to those of healthy teeth. This may be attributed to the resin's low polymerization shrinkage rates, and satisfactory characteristics in terms of hardness, and resistance to abrasion and compression. Furthermore, the adhesive system used to bond composite resins has the ability of moistening and infiltrating into the dentin after the smear layer has been removed by acid etching, which creates micromechanical retention, promoting stress distribution through the dentin, and reducing the chances of fracture.

The association of composite resin with fiberglass posts did not improve the fracture resistance of teeth. According to some authors, ${ }^{27,28}$ endodontically treated anterior teeth with thick dentin walls should be restored with composite resin. Additionally, it has been reported that the fracture resistance of weakened teeth restored with fiber posts does not improve. ${ }^{13,29}$ This may be related to the fact that the main role of intracanal posts is to promote the retention of the filling material onto the remaining

\section{References}

1. Lee GP, Lee MY, Lum SOY, Poh RS, Lim KC. Extraradicular diffusion of hydrogen peroxide and $\mathrm{pH}$ changes associated with intracoronal bleaching of discoloured teeth using different bleaching agents. Int Endod J. 2004 Jul;37(7):500-6.

2. Chng HK, Yap AUJ, Wattanapayungkul P, Sim CPC. Effect of traditional and alternative intracoronal bleaching agents on microhardness of human dentine. J Oral Rehabil. 2004 Aug;31(8):811-6.

3. Pécora JD, Cruz-Filho AM, Sousa-Neto MD, Silva RG. In vitro action of various bleaching agents on the microhardness of human dentin. Braz Dent J. 1994; 5(2):129-34.

4. Pobbe POS, Viapiana R, Souza-Grabriel AE, Marchesan MA, Sousa-Neto MD, Silva-Sousa YTC, Silva RG. Coronal resistance to fracture of endodontically treated teeth submitted to light-activated bleaching. J Dent. 2008 Nov;36(11):935-9.

5. Swift Jr EJ. Critical Effects of bleaching on tooth structure and restorations, part II: enamel bonding. J Esthet Restor Dent. 2008;20(1):68-73. dental structure..$^{12,13,29,30}$

Both restorative procedures tested in this study proved feasible for restoring the fracture resistance of endodontically treated teeth submitted to bleaching. Furthermore, the use of intracanal posts did not increase the resistance of bleached teeth. It should be borne in mind that the experiments of the present study were conducted in healthy teeth; therefore, caution should be taken in extrapolating these results to carious and destroyed teeth. Further studies are necessary to assess other variables involved in the fracture resistance of endodontically treated and bleached teeth.

\section{Conclusions}

Based on the methodology and results of this study, it could be concluded that endodontically treated teeth submitted to dental bleaching and sealed with Coltosol showed the lowest values of fracture resistance. Furthermore, the restorative procedures using composite resin restored the fracture resistance of endodontically treated and bleached teeth, but the association of composite resin with fiberglass posts did not increase fracture resistance more than restoring teeth with composite resin alone.

6. Swift Jr. Effects of bleaching on tooth structure and restorations, part III: effects on dentin. J Esthet Restor Dent. 2008;20(2):1-7.

7. Shannon H, Spencer P, Gross K, Tira D. Characterization of enamel exposed to $10 \%$ carbamide peroxide bleaching agents. Quintessence Int. 1993 Jan;24(1):39-44.

8. Worschech CC, Rodrigues JA, Martins LR, Ambrosano GM. In vitro evaluation of human dental enamel surface roughness bleached with $35 \%$ carbamide peroxide and submitted to abrasive dentifrice brushing. Pesqui Odontol Bras. 2003 Oct-Dec;17(4)342-8.

9. Soldani P, Amaral CM, Rodrigues JA. Microhardness evaluation of in situ vital bleaching and thickening agents on human dental enamel. Int J Periodontics Restorative Dent. 2010 Apr;30(2):203-11.

10. Rodrigues JA, Marchi GM, Ambrosano GM, Heymann HO, Pimenta LA. Microhardness evaluation of in situ vital bleach- 
ing on human dental enamel using a novel study. Dent Mat. 2005 Nov;21(11):1059-67.

11. Tredwin CJ, Naik S, Lewis NJ, Scully C. Hydrogen peroxide tooth whitening (bleaching) products: review of adverse effects and safety issues. Br Dent J. 2006 Apr;200(7):371-6.

12. Bonfante G, Kaizer OB, Pegoraro LF, Valle AL. Fracture resistance and failure pattern of teeth submitted to internal bleaching with $37 \%$ carbamide peroxide, with application of different restorative procedures. J Appl Oral Sci. 2006 Aug;14(4):247-52.

13. Marchi GM, Paulino LA, Pimenta LAF, De Lima FA. Effect of different filling materials in combination with intraradicular posts on the resistance to fracture of weakened roots. J Oral Rehabil. 2003Jun; 30(6):623-9

14. D’Arcangelo C, De Angelis F, Vadini M, D'Amario M, Caputi. Fracture Resistance and Deflection of Pulpless Anterior Teeth Restored with Composite or Porcelain Veneers. J Endod. 2010;36(1):153-6

15. Soares PV, Santos PCF, Martins LRM, Soares CJ. Influence of restorative technique on the biomechanical behavior of endodontically treated maxillary premolars. Part I: Fracture resistance and fracture mode. J Prosthet Dent. 2008 Jan;99(1):307.

16. Attin T, Müller T, Patyk A, Lennon AM. Influence of different bleaching systems on fracture toughness and hardness of enamel. Oper Dent. 2004 Mar-Apr;29(2):188-95.

17. Hannig C, Westphal C, Becker K, Attin T. Fracture resistance of endodontically treated maxillary premolars restored with CAD/CAM ceramic inlays. J Prosthet Dent. 2005 Oct;94(4):342-9.

18. Hansen EK, Asmussen E. In vivo fractures of endodontically treated posterior teeth restored with enamel-bonded resin. Endod Dent Traumatol. 1990 Oct;6(5):218-25.

19. Papa J, Cain C, Messer HH. Moisture content of vital vs endodontically treated teeth. Endod Dent Traumatol. 1994 Apr;10(2):91-3.

20. Helfer AR, Melnick S, Schilder H. Determination of the moisture content of vital and pulp less teeth. Oral Surg Oral Med Oral Pathol 1972 Oct;34(4):661-70.
21. Kishen A, Asundi A. Photomechanical investigations on post-endodontically rehabilitated teeth. J Biomed Opt. 2002 Apr;7(2):262-70.

22. Tam LE, Kuo VY, Noroozi A. Effect of prolonged direct end indirect peroxide bleaching and fracture toughness of human dentin. J Esthet Restor Dent. 2007;19(2):100-9.

23. Kawamoto K, Tsujimoto Y. Effects of the hydroxyl radical and hydrogen peroxide on tooth bleaching. J. Endod. 2004 Jan;30(1):45-50.

24. Carrasco LD, Guerisoli DMZ, Pécora JD, Froner IC. Evaluation of dentin permeability after light active internal dental bleaching. Dent Traumatol. 2007 Feb;23(1):30-4.

25. Sydney GB, Barletta FB, Sydney RB. In vitro analysis of effects of heat used in dental bleaching on human dental enamel. Braz Dent J. 2002;13(3):166-9.

26. Dantas CM, Vivan CL, Ferreira LS, Freitas PM, Marques MM. In vitro effect of low intensity laser on the cytotoxicity produced by substances released by bleaching gel. Braz Oral Res. 2010 Oct-Dec;24(4):460-6.

27. Pontius O, Hutter JW. Survival rate and fracture strength of incisors restored with different post and core systems and endodontically treated incisors without coronoradicular reinforcement. J Endod. 2002 Oct;28(10):710-5.

28. Azevedo RA, Silva-Sousa YT, Souza-Gabriel AE, Messias DC, Alfredo E, Silva RG. Fracture resistance of teeth subjected to internal bleaching and restored with different procedures. Braz Dent J. 2011; 22(2):117-21.

29. Garbin CA, Spazzin AO, Meira-Júnior AD, Loretto SC, Lyra AM, Braz R. Biomechanical behaviour of a fractured maxillary incisor restored with direct composite resin only or with different post systems. Int Endod J. 2010 Dec;43(12):1098107.

30. Bonfante G, Kaizer OB, Pegoraro LF, do Valle AL. Tensile bond strength of glass fiber posts luted with different cements. Braz Oral Res. 2007 Apr-Jun;21(2):159-64. 